\title{
The East Antarctic lce Sheet as a source of sea-level rise: A major tipping element in the climate system?
}

\author{
Christopher J. Fogwill', N.R. Golledge ${ }^{2,3}$, H. Millman' and C.S.M. Turney ${ }^{1}$
}

\begin{abstract}
Sea-level reconstructions suggest significant contributions from the East Antarctic Ice Sheet may be required to reconcile high interglacial sea levels. Understanding the mechanism(s) that drove this loss is critical to projecting our future commitment to sea-level rise.
\end{abstract}

The stability of the Antarctic ice sheets and their potential contribution to sea level under projected future warming remain highly uncertain. In part, this uncertainty arises from comparison with past interglacial periods when, despite only small apparent increases in mean atmospheric and ocean temperatures, eustatic sea levels are interpreted to have been 5-20 meters higher than present (e.g. Dutton et al. 2015). To achieve these highstands, undefined mechanisms or feedbacks that substantially increased the net contribution of the Earth's ice sheets to global sea level must have been at work. Understanding the feedbacks and tipping points that drove sea-level rise during past interglacial periods are therefore not only key to improving sea-level projections over the next century, but critically, given that ice-sheet response times are far longer than those of the atmosphere or ocean, they are important for quantifying our commitment to ice loss and sea-level rise over millennia.

\section{Last Interglacial sea levels}

The Last Interglacial (LIG; 135,000-116,000 years ago) is a key period in this regard; described as a "super-interglacial", empirical evidence suggests that the LIG was only around $2^{\circ} \mathrm{C}$ warmer than pre-industrial times, whilst sea levels were far higher (Turney and Jones 2010). Critically, the LIG was associated with an early rate of global sea-level rise that

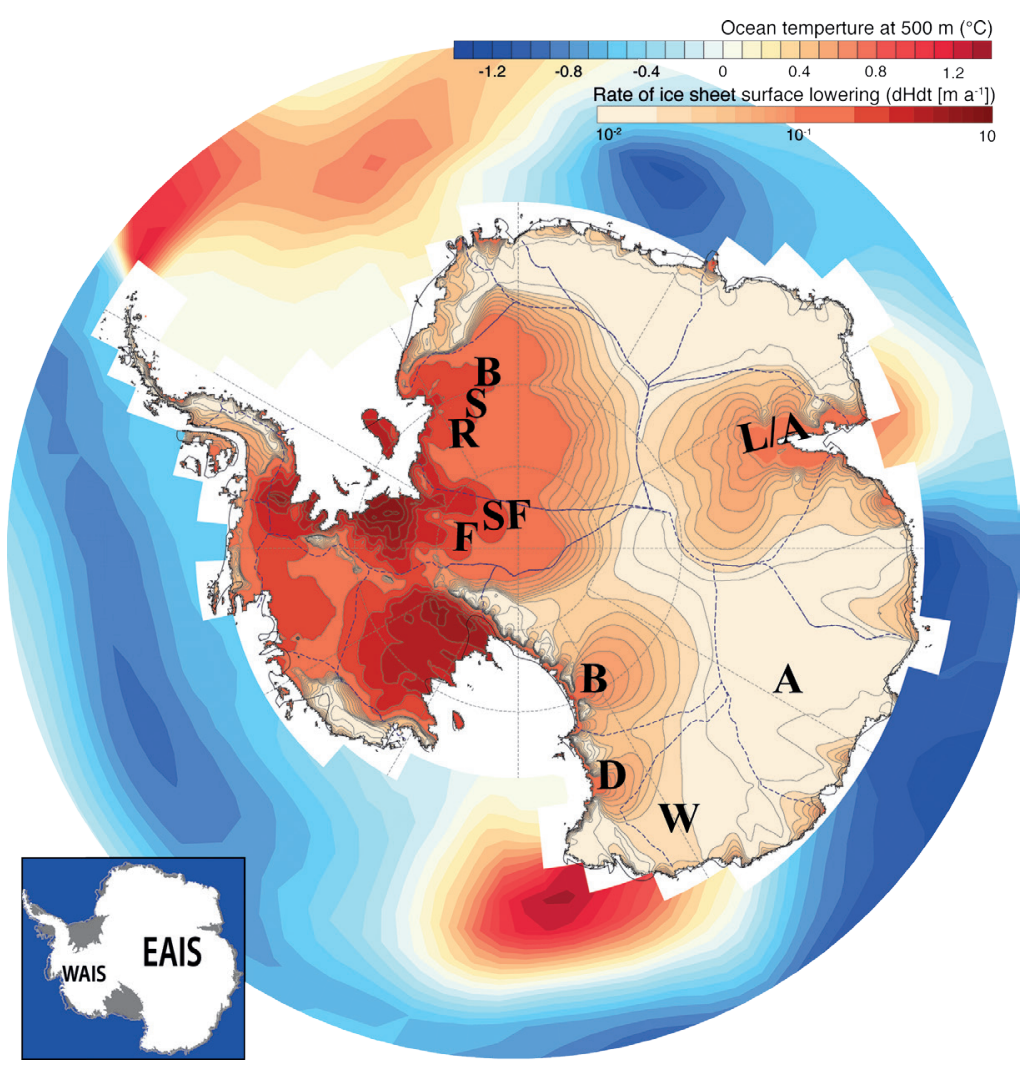

Figure 1: Southern Ocean temperature anomalies at $500 \mathrm{~m}$ depth under $135 \mathrm{ka}$ BP boundary conditions with the Southern Hemisphere Westerlies shifted south (for a Southwards shift Southern Hemisphere westerly winds minus control simulation), together with the pattern of ice-sheet thinning from an independent glacial-interglacial ocean-forcing model experiment using the Parallel Ice Sheet Model (PISM) at $5 \mathrm{~km}$ resolution. The major EAIS drainage basins are marked F: the Foundation, SF: Support Force, R: Recovery, S: Slessor, B: Bailey basins, L/A: the Ambert/Amery basin, B: the Byrd, D: David, W: Wilkes, and A: Aurora. Inset Map of the Antarctic Continent showing WAIS and EAIS. Adapted from Fogwill et al. (2014).

exceeded 5.6 meters per kyr, culminating in global sea levels 6.6-9.4 meters above present (Kopp et al. 2009). At present, the LIG eustatic sea-level-rise budget remains unresolved. Recent reassessments of potential contributions, including ocean thermal expansion (McKay et al. 2011) and wasting of the Greenland and West Antarctic ice sheets, leaves some 0.8 to 3.5 meters of global mean sea level (GMSL) unaccounted for during the LIG. To date, research and media attention has largely focused on the West Antarctic Ice Sheet (WAIS), however the question over the possible contribution made by the far larger East Antarctic Ice Sheet (EAIS) has been raised by both recent contemporary observations (e.g. Greenbaum et al. 2015) and ice-sheet model simulations (e.g. Golledge et al. 2015; Deconto and Pollard. 2016). This raises an important question: might hitherto unidentified mechanisms or feedbacks have induced accelerated mass loss from marine-based sectors of the EAIS?

\section{Ice-sheet model simulations}

Global and regional model-based oceanatmosphere simulations for both future and paleoclimate scenarios are the most powerful tools currently available for establishing both the spatial pattern and variability of environmental perturbations through time, as well as the likely magnitudes of change. This is especially true when such models are empirically constrained, for example, by the verification of model outputs against geological proxy data.

However, to establish likely sea-level changes that may take place under warmer-than-present conditions (either during past interglacials or in the future), it is necessary to employ numerical models capable of accurately simulating the major ice sheets. Together, the Greenland and Antarctic ice sheets act as reservoirs, whose combined freshwater storage capacity must account for the majority of interglacial sea-level variability. The two main ice sheets of Antarctica, the West and the East Antarctic ice sheets contain $\sim 3.9$ and $\sim 51.6 \mathrm{~m}$ sea-level-equivalent ice volume respectively, thus even relatively small changes in their extents and thicknesses may lead to global sealevel changes of several meters. In Antarctic terms, changes in ice-sheet extent over paleoclimate timescales are primarily controlled by oceanic conditions (Joughin et al. 2012), but in both paleo and future ice-sheet model 


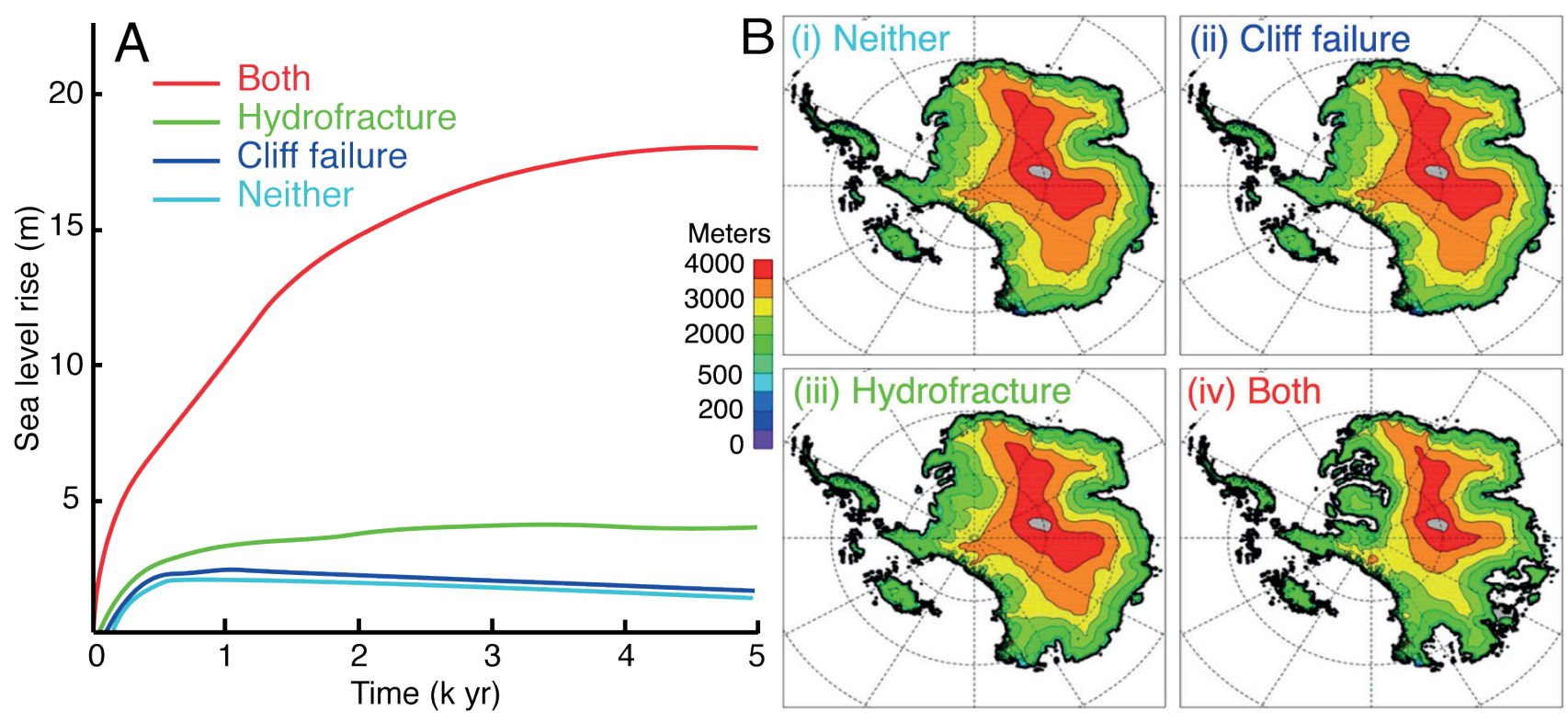

Figure 2: (A) Global mean equivalent sea-level rise in Pliocene warm-climate simulations. Time series of global mean sea-level rise above modern are shown, implied by reduced Antarctic ice volumes. The calculation takes into account the lesser effect of melting ice that is originally grounded below sea level. Cyan: with neither cliff failure nor melt-driven hydrofracturing active. Blue: with cliff failure active. Green: with melt-driven hydrofracturing active. Red: with both these mechanisms active. (B) Ice distribution across the Antarctic continent with (a) neither cliff-failure or melt-driven hydrofraturing, (b) cliff failure active, (c) Melt-driven hydrofrature, and (d) both cliff failure and hydrofracturing incorporated to model simulations equilibrated after 5,000 years of warm-climate forcing. Demonstrating the marked loss of EAIS outlets under scenario $d$ incorporating both cliff failure and hydrofracture. Adapted from Pollard et al. (2015), reprinted with permission of Elsevier.

simulations, inter-model discrepancies may arise because of the manner in which key processes are implemented and parameterized, or the spatial resolution at which experiments are run (Favier et al. 2014).

\section{New directions}

Uncertainties over the sources of sea-level rise during the LIG have driven an increased interest in paleo-ice-sheet model simulations, because empirical data exist with which the models can be "ground-truthed", in contrast to forward projections that are unconstrained. Recent studies have highlighted that the Antarctic ice sheets may be highly sensitive to circulation changes in the Southern Ocean triggered by changes in circulation patterns driven by anthropogenic warming over the next century (Hellmer et al. 2012). To explore the effect that atmospheric circulation changes may have on marine-based sectors of the Antarctic ice sheets during the LIG, Fogwill et al. (2014) examined the role that physical changes in the location of the Southern Hemisphere westerly winds could play in driving WAIS and EAIS change through changing Southern Ocean circulation using Earth System Climate Models (ESCMs). Simulations demonstrated that sectors of the EAIS found to be most sensitive include the Eastern Weddell Sea, the Amery/Lambert region and the western Ross Sea, which when combined could add 3-5 m to GMSL (Fig. 1). Whilst ESCMs provide useful insights into broad scale ocean changes, Regional Ocean Models (ROMs) may prove critical to connect the ice sheet to broad scale ocean circulation changes (e.g. Hellmer et al. 2012).

Paleo-ice-sheet experiments have also been used to explore the possible drivers and mechanisms of EAIS change during past interglacials to provide insights into the future. In one such study, Mengel and Levemann (2014) demonstrated that it is possible to drive self-sustained discharge of the entire Wilkes Basin simply by removing a specific coastal ice volume (termed an ice plug). The GMSL equivalence of such a collapse is on the order of 3-4 $\mathrm{m}$, but the question of how this ice plug could be removed remains unresolved.

One potential scenario involves catastrophic glaciological changes such as ice-shelf hydrofracture and ice-cliff failure. Pollard et al (2015) implemented these two mechanisms on a whole-Antarctic ice-sheet scale for climatic conditions representative of the warm Pliocene. The results of these simulations are dramatic, driving rapid ice-sheet collapse across huge areas of the WAIS and EAIS on centennial timeframes, and producing GMSL equivalence in excess of $\sim 17 \mathrm{~m}$ within millennia (Fig. 2). Whilst the mechanisms are highly parameterized, together ice-shelf hydrofracture and ice-cliff failure provide potential "missing links" in the current generation of ice-sheet models (DeConto and Pollard 2016). They are therefore important candidates for future process studies, given that when combined, their effect is far greater than the sum of their individual effects - it is such strong nonlinearities that are the hallmark of a tipping element. Similarly, there is a need to include more accurate simulation of basal hydrological processes at the ice-sheet scale (Bueler and van Pelt 2015), or the ability for changes in basal friction to effect changes in ice-sheet behavior (Golledge et al 2015).

\section{Conclusions}

To understand and quantify the potential of the EAIS as a major tipping element in the Earth's climate system, future developments are needed so that ice-sheet models incorporate the complex interactions between ice sheets and their beds, their connection to ice shelves, and also the continental- and local-scale atmospheric and oceanic forcings that the ice sheets are exposed to (e.g.
Bracegirdle et al. 2015). Simulating more realistic ice-flow behavior to external drivers is key if we are to robustly model the response of the Antarctic ice sheets to future changes both at the periphery and the bed. With emerging evidence that the EAIS may be highly susceptible to ocean forcing (Greenbaum et al. 2015), and the concept of marine-ice-sheet instability becoming increasingly accepted and well understood, parameterizing the non-linear mechanisms occurring at the ice-ocean interface is essential if we are to reduce uncertainty in future sea-level rise projections.

\section{AFFILIATIONS}

${ }^{1}$ Climate Change Research Centre, University of New South Wales, Sydney, Australia

${ }^{2}$ Antarctic Research Centre, Victoria University of Wellington, New Zealand

${ }^{3}$ GNS Science, Lower Hutt, New Zealand

\section{CONTACT}

Christopher J. Fogwill: c.fogwill@unsw.edu.au

\section{REFERENCES}

Bracegirdle TJ et al. (2015) BAMS 97: ES23-ES26

Bueler E, van Pelt W (2015) Geosci Model Dev 8: 1613-1635

Dutton A et al. (2015) Science 349, doi: 10.1126/science. aaa4019

DeConto RM, Pollard D (2016) Nature 531: 591-597

Favier L et al. (2014) Nature Clim Change 4: 117-121

Fogwill CJ et al. (2014) J Quat Sci 29: 91-98

Golledge NR et al. (2015) Nature 526: 421-425

Greenbaum JS et al. (2015) Nature Geosci 8: 294-298

Hellmer HH et al. (2012) Nature 485: 225-228

Joughin I et al. (2012) Science 338: 1172-1176

Kopp RE et al. (2009) Nature 462: 863-867

McKay NP et al. (2011) Geo Res Lett 38, doi:10.1029/2011GL048280

Mengel M, Leverman A (2014) Nature Clim Change 4 451-455

Pollard D et al. (2015) Earth Plan Sci Lett 412: 112-121

Turney CSM, Jones RT (2010) J Quat Sci 25: 839-843 